\title{
Angiotensin Converting Enzyme Inhibitors and Angiotensin II Receptor Antagonists on Residual Renal Function Preservation in Peritoneal Dialysis Patients
}

\author{
Reyes Marin Fernando Arturo* \\ Hospital Issemym Tlalnepantla, Mexico
}

*Corresponding author: Reyes Marin Fernando Arturo, Hospital Issemym Tlalnepantla, Mexico, Email: artmar@prodigy.net.mx

\section{Short Communication}

Angiotensin-converting enzyme inhibitors (ACEi) and angiotensin II receptor blockers (ARBs) are recommended in peritoneal dialysis (PD) patients for hypertension or heart failure control [1] Angiotensin II (AII) is an important factor in the development of renal fibrosis due to its hemodynamic effects on glomeruli and stimulation of extracellular matrix proteins synthesis, mediated by TGF $\beta$ [2]. This may explain why treatment with ACEi and ARBs is renoprotective in patients with diabetic and non-diabetic nephropathy $[3,4]$.

Treatment with ACEi and ARBs has been shown to be associated with decreased risk of RRF decline in PD patients [5]. The use of renin-angiotensin-aldosterone system blockade was independently associated with a $32 \%$ decrease in the development of anuria in patients with chronic renal failure irrespective of the dialysis modality and $70 \%$ decrease in mortality of PD patients treated with either ACEi or ARBs therapy has been shown [5]. It is tempting to speculate that the improved survival may have been related, at least in part, to preservation of RRF by the use of these agents. It was shown that ramipril significantly reduced the rate of RRF decline and delayed the development of complete anuria in prevalent CAPD patients after 12 months, when it was compared with placebo in two groups; average rGFR declined $2.07 \mathrm{ml} / \mathrm{min}$ per $1.73 \mathrm{~m}^{2}$. The difference between the average changes in rGFR in the 2 groups from baseline to 12 months was $0.93 \mathrm{ml} / \mathrm{min}$ per $1.73 \mathrm{~m}^{2}$ (95\% CI 0.09 to $1.78 \mathrm{ml} / \mathrm{min}$ per $1.73 \mathrm{~m}^{2}$ ] [6]. Another approach to inhibiting the renin-angiotensin system is ARBs administration. It was demonstrated that RRF and daily urine volume were significantly better preserved in CAPD patients on valsartan $(3.4 \pm 0.3$ to $\left.4.3 \pm 0.7 \mathrm{ml} / \mathrm{min} / 1.73 \mathrm{~m}^{2}\right)$ as compared to controls $(5.9 \pm 0.5$ to $2.8 \pm 0.4 \mathrm{ml} / \mathrm{min} / 1.73 \mathrm{~m}^{2}$ ) [7].
Although these two studies were small, they showed that drugs with renoprotective effects continue to exert benefits in patients with stage 1-4 chronic kidney disease (CKD) and slow the progression to anuria in stage 5 CKD patients on dialysis and thus should be continued in all dialysis patients with residual renal function. Recently the time course of decline of rGFR in 452 incident non-anuric PD patients was followed-up for 3 years after the start of dialysis; one group of patients received ACEi/ARBs and the other was the control group. The time course of decline of rGFR was not different between the 2 groups over the 3 years of PD treatment [8]. To test the hypothesis that losartan is at least equal to enalapril in preserving RRF in APD patients, we conducted a randomized clinical trial with a 1-year follow-up period. Unlike previously reported studies, our objective was to compare two good pharmacological options for RRF preservation in PD patients [9]. Our results showed that RRF declined progressively over 1 year of follow-up in both groups. At the beginning of the study the RRF was similar and the RRF loss along the follow-up period was similar in both groups; proteinuria was similar in the two groups at the beginning and at the end of the study. The urine output declined progressively during the study in both groups and there were similar proportions of patients with anuria in both groups at the end of the study. We did not demonstrate differences between enalapril and losartan in slowing RRF decline in patients on APD. Any of them may be a suitable alternative for RRF preservation in young APD patients. At the present time ACEi and ARBs are effective in the preservation of the residual renal function, in patients with peritoneal dialysis.

\section{References}

1. (2004) K/DOQI Clinical practice guidelines on hypertension and antihypertensive agents in chronic kidney disease. Am J Kidney Dis 43: $1-290$. 
2. Brenner BM, Cooper ME, de Zeeuw D (2001) Effects of losartan on renal and cardiovascular outcomes in patients with type 2 diabetes and nephropathy. N Engl J Med 345: 861-869.

3. Ruggenenti P, Perna A, Gherardi G, Garini G (1999) Renoprotective properties of ACE-inhibition in non-diabetic nephropathies with nonnephrotic proteinuria. Lancet 354: 359-364.

4. Griffin KA, Bidani AK (2006) Progression of renal disease: Renoprotective specificity of renin-angiotensin system blockade. Clin J Am Soc Nephrol 1: 1054-1065.

5. Fang W, Oreopoulos DG, Bargman JM (2008) Use of ACE inhibitors or angiotensin receptor blockers and survival in patients on peritoneal dialysis. Nephrol Dial Transplant 23: 3704-3710.
6. Li PKT, Chow KM, Wong TYH (2003) Effects of an angiotensin-converting enzyme inhibitor on residual renal function in patients receiving peritoneal dialysis. Ann Intern Med 139: 105-112.

7. Suzuki H, Kanno Y, Sugahora S (2004) Effects of an angiotensin II receptor blocker, valsartan, on residual renal function in patients on CAPD. Am J Kidney Dis 43: 1056-1064.

8. Kolesnyk I, Noordzij M, Dekker FW (2011) Treatment with angiotensin II inhibitors and residual renal function in peritoneal dialysis patients. Perit Dial Int 31: 53-59.

9. Reyes Marín FA, Calzada C, Amato DM (2012) Comparative study of enalapril vs losartan on residual renal function preservation in automated peritoneal dialysis. A randomizaed controlled study. Rev Inv Clin 64: 315-321.

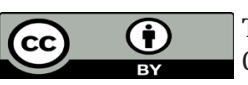

This work is licensed under Creative Commons Attribution 4.0 License

To Submit Your Article Click Here: Submit Article

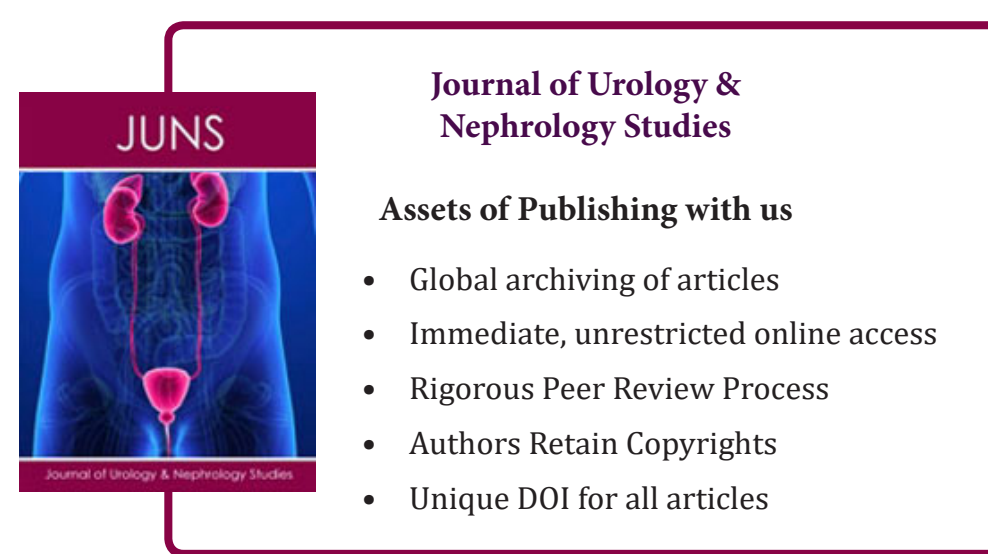

